\title{
Cosmological Views of Anania Shirakatsi
}

\section{S. V. Farmanyan ${ }^{1}$, A. M. Mickaelian²}

NAS RA M. Abeghyan Institute of Literature, Armenia

NAS RA V. Ambartsumian Byurakan Astrophysical Observatory (BAO), Armenia

E-mail: sona.farmanyan@mail.ru

\begin{abstract}
Since the ancient times the usage of cosmological ideas in mythology and poetry has contributed to the formation and development of human's philosophical thought.It is believed that before the M. Mashtots'salphabet, ancient Armenians have expressed their astronomical knowledge through stone structures and rock art.In the Armenian reality, the cosmological views, the idea of the spherical shape of the Earth and information of other celestial bodies more vividly were manifested in the works of Movses Khorenatsi, David Anhaght ( $5^{\text {th }}$ century) and Anania Shirakatsi $\left(7^{\text {th }}\right.$ century).Anania Shirakatsi is an Armenian Astronomer, Mathematician, Philosopher, Geographer and Alchemist.The importance of his work is also noted by foreign authors and he was called $7^{\text {th }}$ century Cosmologist, First Scientist of Armenia and Middival Astronomer.Shirakatsi's works are united in his comprehensive knowledge, his insight of the mind, the ability of combining and analyzing facts and his literature talent.His works have simultaneous historical, cosmic, geographical, religious, literary and mystical significance. In the present study we will show Anania Shirakatsi's cosmological ideas and observations.
\end{abstract}

\section{Introduction}

In the medieval Armenian literature, Shirakatsi was the first author who distinguished and developed natural sciences as independent sciences, thus becoming the founder of natural sciences in Armenia.The source of Shirakatsi's research was: Yeznik Koghbatsi "Yeghts Aghandots", Yeghishe "Meknutyun Araratsots", David Anhaght "Sahmank Imastutyan", Ptghomeos "Almaghest", Kosma Hindikoplevst "Kristoneakan Teghagrutyun", Barsegh Kesaratsi "Vecorya", Keghts Aristotel "Yaghags Ashkharhi", Yepipan Kipratsi "Tankagin Karer", Grigor Nyusetsi "Yaghags Kazmutyan mardoy", Yvsebios Kesartsi "Kronikon" and other works. However, Shirakatsi often criticized those authors and brought his scientific observations.Besides, in almost all his works Shirakatsi used the Bible. Especially, 
Shirakatsi'sCosmological works are of great value (see R. Abramian and B. Tumanyan, K. Ter-Davtyan and S. Arevshatyan, A. Abrahamyan). For some of his works have been dedicated to books or other works by individual authors, such as "Cosmology" ( $\mathrm{K}$. Ter-Davtyan, S. Arevshatyan, 1962), "Astrology" and "Heavenly phenomena" texts, "The Sun in Constellations" and "Moon Period" (A. Abrahamyan, 1960), as well as a number of works dedicated to the calendars, which are also based on astronomical knowledge such as"Lunar Vernal Equinoctial Tables", "Moon's Special Rotund", "Moon-showing Tables" (A. Abrahamyan, 1962), "532 Years Table" (A. Abrahamyan, 1940), "Kharnakhoran" (G. Brutian, 1998),"Peoples' Months Names" andArmenian Ancient Months and Hours Names (H. Acharyan, 1950).Shirakatsi's main cosmological views are expressed in his "Cosmology" work (K.S. Ter-Davtyan, 1962) which is based on ancient Greek Astronomy, further transformations and his personal observations.

It should be noted that in the era of Shirakatsi Greek science has been declining,and Arabic science (in particular, highly advanced Astronomy) still had to be developed, so maintaining valuable knowledge and, in some cases, even developing it was a difficult task.The work "Cosmology" has a great literary and scientific value, The Shirakatsi wrote it with beautiful examples and figurative descriptions.It covers the following ten chapters:

1. "Mathematician Anania Shirakatsi's words to those who have promised a brief introduction"(Anania Shirakatsoy hamaroghi ar khostacealn)

2. "About Sky" (Yaghaks Yerkni)

3. "About Earth" (Yaghaks Yerkri)

4. "About Sea" (Yaghaks Tsovu)

5. "About Celestial Treasures" (Yaghaks Yerknayin Zardots)

6."AboutMovements and Phenomena Occurring between Heaven and Earth"(Yaghaks vor i mech Yerkni yev Yerkri en sharjmunk yev tesytunk)

7. "About Milky Way" (Yaghaks Tsir Katni)

8. "About the Northern Stars" (YaghaksHyusisayin Asteghats)

9. "About Moon" (Yaghaks Lusni)

10. "About Sun" (Yaghaks Aregaki)

It should be noted that in the $7^{\text {th }}$ century, it was still difficult to separate the Earth and the seas from the Universe, because the perception of the world was one, and everything unattainable was mysterious,including the seas and oceans, as long as geographical journeysdid not start.Moreover, any travel was limited, so many monthes was needed to travel from Armenia to Greece or Rome.That is why the 
"world" and, accordingly, the perception of the world was limited.

\title{
Mathematician Anania Shirakatsi's Words to Those who have Promised a Brief Introduction
}

"Mathematician Anania Shirakatsi's Words to those who have Promised a Brief Introduction"work was copied by Ghukas (son of David) in 971.The manuscript is a collection of historiographical materials, but some pages have not been preserved.The Shirakatsi precisely expresses his attitude towards pagan scholars and church fathers. He wants to take advantage of the "externalities that the Apostle Paul commands and rejects the sayings of the pagan scholors of the wise, who refused to recognize the existence of God as an existence, The basis of this material and existence" (A. Abrahamyan, 1940). Anyway, Shirakatsi considered it worthy to mention the observations of the ungodly and then reject them in order to show the virtue and wisdom of the great fathers. About 14 centuries ago, Shirakatsi manifested a special approach to modern scientific and literary works, when the previous work on the subject was analyzed,in order to clarify the right and wrong thoughts expressed in them.

\begin{abstract}
About Sky
"About Sky"work was copied by Priest Grigor in 1342.This chapter is devoted to the essence of heaven and its discovery, which begins with a simple concept of scientific methodology.Shirakatsi noticed that for himself and for all those who are doing exact sciences, the sayings of glorious ancestors seem to be true and that everything they say can be explained in terms of words and accessible to reason.In this chapter, talking about the sky, Shirakatsi separates the upper sky and the inner heaven.In his opinion, the upper sky as the Greeks call is "airtime", and the Chaldeans call it "flaming fire" "this is an unmatched body, a simple fire, which has come from nothing and nothing has arisen from it,... it blocks all kinds of creatures inside and all the elements closely surrounding the inferior sky.And it is enough for him to expand his circle, which blocks everything from the outside,in order to show the spherical globe of its vast expanse ... and under the arch, matched by its shape, it is the place where we call heaven.They say that it is air and water, not frozen or condensed, but real water, in liquid form, like a heavenly one.Like after the rain, air bubbles come out of the air,which are round shaped under the air and moisture of the rain, such as a dome,so is the heavenly institution, which is surrounded by a circular shape as a result of air blowing (A. Abrahamyan, 1940): Shirakatsi's words speak out both of his
\end{abstract}


admiration for heaven,as a phenomenon above everything else, and both his knowledge and comparative analytic mind.

\begin{abstract}
About Earth
Shirakatsi's "About Earth" chapter starts with more representation of more common ideas.Some pagan "good" philosophers say that Earth looks like a tray.And some of them say that it's spherical or that it is a six angled cube that has been raised and placed in the center of the sky by the force of the wind, pushing the Earth down. Shirakatsiis for the idea that the Earth is spherical one, which proves his ability to correctly orientate in many facts.
\end{abstract}

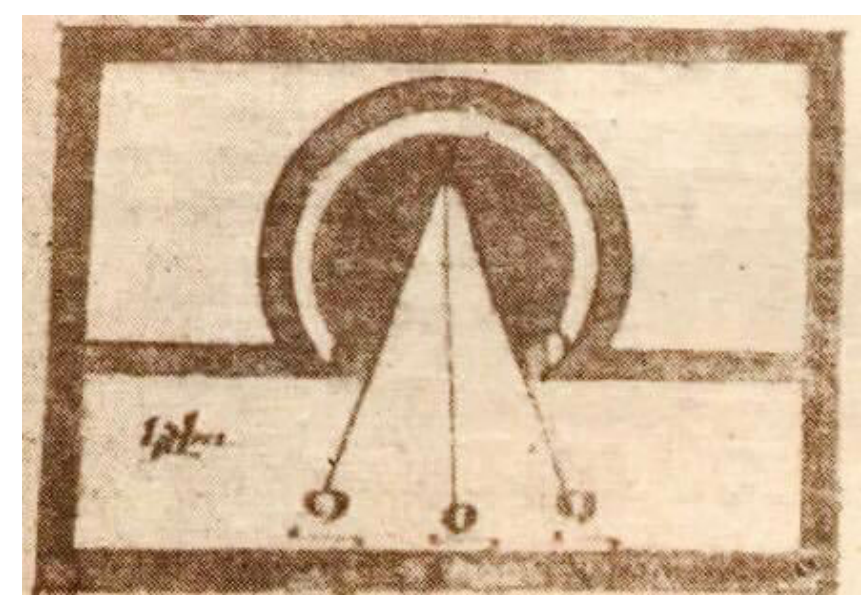

Figure 1. Earth centered Universe by Anania Shirakatsi

He thinks that the Earth is like an egg, and is colored spherical situated in the middle, the protein around it, and the peel is surrounded by four sides,likely the Earth is right in the middle, the air around it, and the sky is surrounded by all four sides."Such an idea was consistent with the Indo-European, Egyptian, and Chinese mythologies about the cosmic myth about the World Egg" (V. Toporov, 1992).Shirakatsi comes from the idea of the earth's spheres as well as explaining the formation of night and day.

To his mind the daytime emerges from the Sun and its light, and the night comes out of the shadow, which falls from the mass of the Earth. According to Shirakatsi, when the Earth's shadow falls on half the globe, we are in the night, and in the opposite half is the day. 


\section{About Sea}

In the chapter "About Sea", Shirakatsi speaks about the outer sea that surrounds the Earth and about the seas and lakes on the Earth. On these issues Shirakatsi cites "evil" and "good" philosophers' opinions.Shirakatsi agrees with "good" philosophers, considering that the seas are on the earth and that "there is no other sea outside the country" (A. Abrahamyan, 1940).Shirakatsi tries to explain the reason for being present at the Earth's Center of the Universe for a rational reason, rejecting the idea of being placed on the water.He claims that the Earth maintains its position as a result of a rapid cycling of heavenly zones and two opposing forces,Earth's gravity and wind forces that balance each other.The heaviness of the Earth stretches it down, and the strength of the winds upward, and so it is balanced, retains its stable position in the center of the Universe.He asserts that these seas are divided by borders, but they form a whole, they are connected to each other, though they are far from the outer boundaries.In this section, Shirakatsi also mentions about the sea water balance and the saltiness and bitterness of the waters.According to Shirakatsi, the cause of water intoxication and bitterness is evaporation caused by the solar heat. "The heat of the sun reduces the excess of water and leads to the sweetness of the water" (A. Abrahamyan, 1940):Here, Shirakatsi's united worldview is manifested, and finding parallels between the sea and the Sun, he also substantiates the involvement of the work of the seas in his "Cosmology".

\section{About Celestial Treasures}

"About Celestial Treasures" section Shirakatsi speaks about astrology in details, considering it "foolishness" and "misguidance".Shirakatsi considers meaningless work to tell about Haldians observations about celestial bodies. Anyway, in order to inform his reader, Shirakatsi narrates on several pages the Haldian art of astronomical constellations and planets using astrology. He notes that astronomical science has begun and developed by the Chaldeans, and later on by the Egyptians and Greeks.Shirakatsi believes that in parallel with it, the Chaldeans have also created astronomy, which was gradually spreaded to other countries. The Chaldeans referred to heavenly bodies and the constellations to divine attributes and to the fate of the human being, to the duration of his life, and to his actions during his lifetime.It should be noted that the denial of astrology is one of the most crucial steps by Shirakatsi.Until the 17th and 18th centuries, some astronomers continued to believe in the influence of stars on destiny, and asrology in the form of horoscopes are still acceptable by many. 


\section{About Movements and Phenomena Occurring between Heaven and Earth}

In the chapter "About Movements and Phenomena Occurring between Heaven and Earth", Shirakatsi thoroughly describes the essence of wind, cloud, rain, hail, snow, lightning, thunder, rainbow and other atmospheric phenomena.Shirakatsi believed that atmospheric phenomena were happening at the same time, but the eye sees only the scene of the phenomenon, and the ear will hear it only after a while until the voice reaches us from the scene.In fact, Shirakatsi was well aware that the speed of light propagation was much greater than the speed of the sound. "Scientists of the time did not know the actual speed of light or sound, they were determined later in the 18th-19th centuries (L. Nazaryan, 2003): Again, talking about these heavenly phenomena, Shirakatsi manifests a common perception of the world and tries to find a connection between all phenomena.

\section{About Milky Way}

In the chapter "About Milky Way" Shirakatsi compares the Myths about the Milky Way to the myths of various peoples without agreeing with none of them.Shirakatsi also mentions an ancient Armenian tradition, according to which Vahagn stole the royal stump of Assyrian King Barsham on his way to Armenia and drowned in the sky and now it shines.For this reason, in the Middle Ages, Milky Way in Armenian was called "The Way of Stump Stoler". Criticizing myths, Shirakatsi gives a scientific explanation of the Milky Way."Throw all this and do not believe in such things as they are many large and small stars that are accumulated in a blend of light" (A. Abrahamyan, 1940). "Sometimes, the idea of the Milky Way starry character is attributed to Shirakatsi, considering that he had understood a thousand years before the creation of the telescope, that this zone actually consists of many far awaystars (H. Harutyunian, A. Mickaelian, 2014). It should be noted that the Milky Way stellar composition was revealed only in the 17 th century by Galileo Galilei.

\section{About the Northern Stars}

Unlike the other chapters, In the chapter "About the Northern Stars" Shirakatsi does not refer to "good" philosophers and does not criticize "evil" philosophers. Instead, he briefly presents his ideas and observations about the Northern Stars. He assures us that the stars that are called the heavenly pole are neither rise nor set into the moon, but are traveling with a man, whether on the land or on the sea.He is referring to the Polar Star and some of the weaker stars around it that are constantly visible in the 
sky. Shirakatsi considers the stars as gift from God, as it directs people to sailing.This is reflected in Shirakatsi's broad way of thinking and travel experience, as being Armenian scientist whose country does not have a seafront, speaks about remote navigation, which, in fact, had not yet expanded.

\section{About Moon}

In the chapter of the "About Moon" Shirakatsi mentions that the Moon is a thick, hard and spherical body that does not have its own light and is illuminated by the sunlight. Shirakatsi also mentions the occurrence of the Moon's sphases.According to him, the Moon does not always have the same shape, once it grows, once it becomes thick one, while they are in the same direction during the circle, at that time the Sun illuminates the upper part of the Moon, and the bottom remains mysterious.Then the Moon leaves the Sun and we see its lighted part. In this chapter, Shirakatsi also interprets the eclipses of the Sun and the Moon. He writes that the Moon is the cause of the solar eclipse, as the Sun, covers the light coming to us.Shirakatsi also thinks that sea fluxes and refinements are also tied to Lunar phases. The Shirakatsi conceptions about the Moon and its influence essentially coincide with modern ideas.

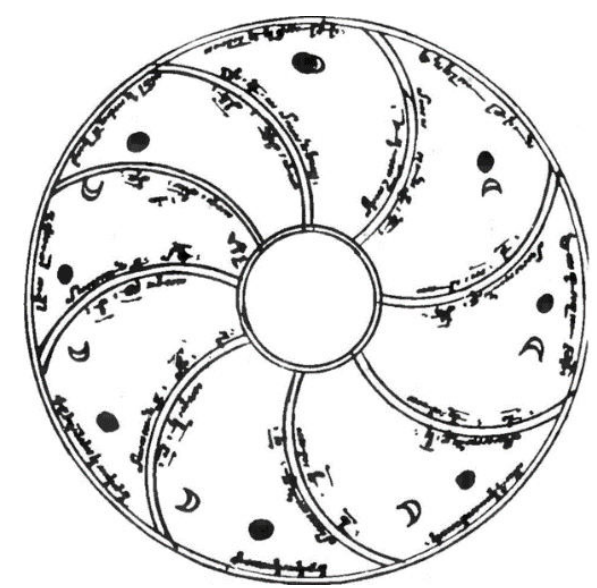

Figure 2. Phases of the Moon

\section{About Sun}

The "About Sun" chapter was copied in $\mathbf{1 6 8 7}$ by Martiros writer. In this chapter, Shirakatsi adheres to ancient philosophers, recognizes that the Sun is a solid, spherical body, its warmth and lighting gets from the Arpi (Sun light) and drives to the atmosphere by which it illuminates and warms the Earth.Shirakatsi notes that the Sun, Moon, and many stars move from West to East, but those celestial bodies, wherever they are, are shown to people with the same size. And in the sky they are 
small, as they are far away and not small in size.According to Shirakatsi, the Sun exceeds its size by the Moon and the Earth.Here Shirakatsi also mentions the occurrence of the seasons and the night and day shifts. He links the seasons of the year with the visible movement of the Sun in heaven, not the axis of the Earth.

\section{Conclusion}

In the field of cosmology, these problems were perhaps the most important thing for a seventh century educated reader or for students who were keen on learning. In the current stage development of Astronomy and Astrophysics most of these fields remain modern one, especially for the public at large and from the point of effects of heavenly bodies on human kind (H. Harutyunian, A. Mickaelian, 2014).By summarizing Shirakatsi's cosmological views, B. Tumanian in his "History of Armenian Astronomy" work presents the following to conclusions:

1. His adopted idea of Earth-centered system, position of the Sun, and the presence of the fire arch is unique and differs from well-known earth-centered systems.

2. Shirakatsi with great diligence studied the works of his predecessors and scholars of his time, he approached them critically, combined with his own studies and gave probable and natural conclusions.

Shirakatsi's works are united in his comprehensive knowledge, his insight of the mind, the ability of combining and analyzing facts and his literature talent.His works have simultaneous historical, cosmic, geographical, religious, literary and mystical significance.

\section{References}

Abeghyan, M. 1944, History of Armenian Old Literature, book A, Yerevan, 571 p. Abrahamyan, A. 1960, Shirakatsi's Newest Astronomical Charts - From the History of Natural Sciences and Techniques, Yerevan, No. 1, 291 p.

Abrahamyan, A. 1962, Lunar Seasons, Yerevan, 109 p.

Abramian, R.; Tumanian, B. 1956, Historical and Astronomical Studies, vol. II, p. 239346

Acharyan, H. 1950, Haykakank, Shirakatsi - A Bulletin of the RA National Academy of Sciences, No. 12, p. 47. 
Brutian, G. 1987, Ananias Shirakatsi's "Harmony" - Mother See of Holy Etchmiadzin Echmiadzin, 1998, page 111.7. E. Danielyan, The Legendary Originals of Bold Philosophy, Science and Technology, Yerevan, N 5, 53 p.

Harutyunyan, H.; Mikayelyan, A. 2014, Collection of Materials of Historical-Scientific Conference Dedicated to 1400th Anniversary of Anania Shirakatsi, Yerevan, 220 p.

Mirumyan, K. 1998, Anania Shirakatsi, Yerevan,169 p.

Nazaryan, L. 2003, Anania Shirakatsi. The Great Medieval Thinker and Scientist, Yerevan, $190 \mathrm{p}$.

Petri, W. 1964, Ananija Schirakazi - EjnArmenischer Kosmograph des 7. Jahrhunderds, Zeitschrift der Deutschen Morgenlandischen Gesellschaft, B. 114, München, p. 86-131

Semenov, L. 1953, Anania Shirakatsi as an Astronomer, "Echmiadzin", p. 7-8

Ter-Davtyan, K.; Arevshatyan, S. 1962, Anania Shirakatsi and his Cosmographic Works - Anania Shirakatsi. Cosmography. Yerevan, p. 210

Ter-Davtyan, K.; Arevshatyan, S. 1962, AnaniaShirakatsi and his Cosmographic Works - AnaniaShirakatsi. Cosmography. Yerevan, p. 122

Toporov, V. 1992, World Egg, Myths of the Peoples of the World, Moscow, p. 230 Tumanyan, B. 1985, History of Armenian Astronomy, Yerevan, 296 p.

Tumanyan, B. 1991, Anania Shirakatsi, Yerevan, 64 p. 